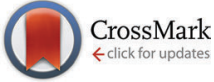

Cite this: New J. Chem., 2016, 40, 9853

Received (in Victoria, Australia) 25th July 2016,

Accepted 4th October 2016

DOI: $10.1039 / c 6 n j 02277 d$

www.rsc.org/njc

\section{"Host-guest" binding of a luminescent dinuclear Au(I) complex based on cyclic diphosphine with organic substrates as a reason for luminescence tuneability $\dagger$}

\author{
Nataliya A. Shamsutdinova, Igor D. Strelnik, Elvira I. Musina, Tatyana P. Gerasimova, \\ Sergey A. Katsyuba, Vasily M. Babaev, Dmitry B. Krivolapov, Igor A. Litvinov, \\ Asiya R. Mustafina, * Andrey A. Karasik and Oleg G. Sinyashin
}

\begin{abstract}
This work introduces a luminescent dinuclear $\mathrm{Au}(\mathrm{l})$ complex with a cyclic PNNP ligand $\left((\mathrm{AuCl})_{2} \mathrm{~L}\right)$ as a "host" molecule with two binding sites, "upper" and "lower". The "upper" binding site is nucleophilic due to two preorganized $\mathrm{Au}-\mathrm{Cl}$ moieties, while the "lower" one is electrophilic due to positive partial charges of hydrogen atoms of $\mathrm{P}-\mathrm{CH}_{2}-\mathrm{N}$ moieties. The "host-guest" binding is a reason for both solvent- and substrate-induced tuning of the complex luminescence. Organic cations, namely $N$-methylpyridinium and trimethylammonium, are revealed as substrates able to bind via the "upper" site of the complex. Acetone, diphenylketone, DMSO, DMF and acetonitrile exemplify substrates able to bind with both the binding sites of the complex. The binding via "lower" sites leads to changes in mutual arrangement of pyridyl moieties and $\mathrm{P}-\mathrm{Au}$ bonds of the complex, which results in a more pronounced effect on the excited state energy relative to the binding via the "upper" site. Substrate-induced tuning of the luminescence is affected by the nature of the solvent due to competitive "host-guest" binding of $(\mathrm{AuCl})_{2} \mathrm{~L}$ with solvent molecules.
\end{abstract}

\section{Introduction}

Stimuli responsive luminescence of $\mathrm{Au}(\mathrm{I})$ complexes makes them promising candidates for sensing, which is a reason for increasing interest in the design and investigation of their new representatives. ${ }^{1-6}$ Indeed, the capacity of $\mathrm{Au}(\mathrm{I})$ complexes for sensing is well documented for crystal samples, where substrateinduced modification of crystal packing results in a luminescence response to vapor exposition or so-called vapochromism..$^{5-7}$

Sensing capacity of any complexes in solutions requires tuneability of their luminescence by noncovalent interactions with metal centers or constituting ligands. Literature data highlight the importance of subtle noncovalent interactions in the energies of both the ground and excited states of $\mathrm{Au}(\mathrm{I})$ complexes, ${ }^{8,9}$ which results in substrate-induced tuneability of their emission in solutions. Sensing capacity of $\mathrm{Au}(\mathrm{I})$ complexes in solutions is exemplified by alkynyl-gold(I) calixarenes or crowns used for cation recognition in solutions. ${ }^{10-15}$ Despite numerous studies on the application of luminescent $\mathrm{Au}(\mathrm{I})$

A. E. Arbuzov Institute of Organic and Physical Chemistry, Kazan Scientific Center of Russian Academy of Sciences, Arbuzov str., 8, 420088, Kazan, Russia.

E-mail: asiyamust@mail.ru

$\dagger$ Electronic supplementary information (ESI) available. CCDC 1495007 and 1495008. For ESI and crystallographic data in CIF or other electronic format see DOI: 10.1039/c6nj02277d complexes in sensing of metal ions and anions, ${ }^{16-18}$ to the best of our knowledge there have not hitherto been any reports on sensing of organic cations and molecules in solutions.

Phosphine derivatives represent very promising types of ligands for $\mathrm{Au}(\mathrm{I})$, since phosphine groups provide efficient coordination of the metal ions, while other substituents can be engaged in supramolecular assembly or substrate recognition. ${ }^{16,19-22}$ The photophysical properties of $\mathrm{Au}(\mathrm{I})$ complexes with phosphine derivatives are strongly dependent on the structural features and electronic characteristics of the constituting ligands. ${ }^{16-18,23-25}$ Moreover, luminescence of $\mathrm{Au}(\mathrm{I})$ phosphine complexes can also be tuned by any non-covalent interactions with metal centers and constituting ligands, which can affect the charge distribution or induce conformational changes within the complexes. ${ }^{18}$

The previously documented synthetic strategy ${ }^{26,27}$ enables us to get series of cyclic diphosphine ligands with different nature of substituting groups in order to vary electron donating or accepting capacity of the ligands. Recently published work reports synthesis and vapochromism of a binuclear phosphinechloride $\mathrm{Au}(\mathrm{I})$ complex with a cyclic diphosphine PNNP ligand $\left((\mathrm{AuCl})_{2} \mathrm{~L}\right.$ in Scheme 1$) .{ }^{28}$ This work suggests that vapochromism of the complex luminescence arises from multipoint "hostguest" like binding of complex $(\mathrm{AuCl})_{2} \mathrm{~L}$ with acetone molecules. The present work is aimed at revealing "host-guest" binding of $(\mathrm{AuCl})_{2} \mathrm{~L}$ with organic molecules and cations as a reason for 


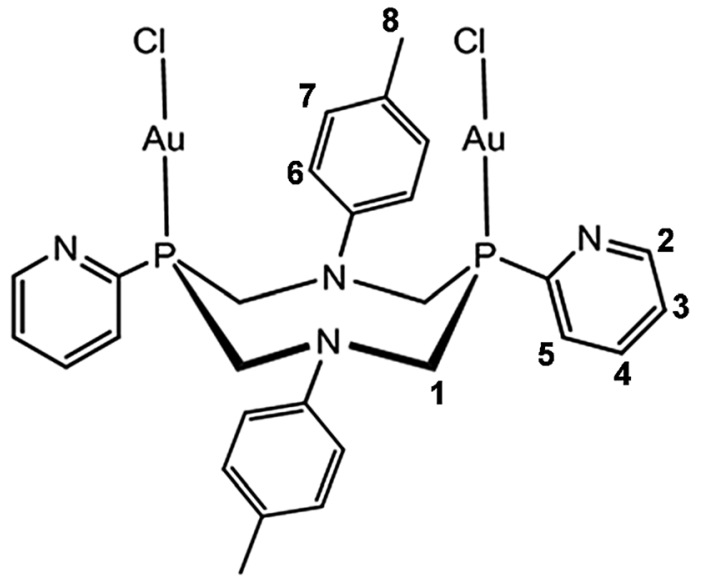

Scheme 1 Structure of $(\mathrm{AuCl})_{2} \mathrm{~L}$.

tuning the complex luminescence in solutions. Moreover, main factors responsible for the capability of $(\mathrm{AuCl})_{2} \mathrm{~L}$ to the substrate responsive emission in solutions will also be highlighted in the report.

\section{Experimental section}

\section{Materials}

Dimethyl sulfoxide (DMSO), N,N-dimethylformamide (DMF), acetone, acetonitrile (AN), dichloromethane (DCM) and diphenyl ketone (DPK) were purchased from Sigma-Aldrich. Solvents were purified according to the common procedures, ${ }^{29}$ dried, deoxygenated, distilled before use, and kept under molecular sieves of 4 Å. DPK was used as received without further purification.

\section{Synthesis}

Dichloro[1,5-bis( $p$-tolyl)-3,7-bis(pyridine-2-yl)-1,5-diaza-3,7diphosphacyclooctane]digold(I). 1,5-bis( $p$-tolyl)-3,7-bis(pyridine2-yl)-1,5-diaza-3,7-diphosphacyclooctane (L) was synthesized by the published method ${ }^{30}$ under an argon atmosphere. Dichloro[1,5-bis(p-tolyl)-3,7-bis(pyridine-2-yl)-1,5-diaza-3,7-diphosphacyclooctane]digold $(\mathrm{I})\left((\mathrm{AuCl})_{2} \mathrm{~L}\right)$ was synthesized according to the described method. ${ }^{28}$ All manipulations with $(\mathrm{AuCl})_{2} \mathrm{~L}$ were carried out under normal conditions without an inert atmosphere. After manipulations no oxidized compounds were detected.

NMR ${ }^{1} \mathrm{H}\left(400 \mathrm{MHz}, 303 \mathrm{~K}\right.$, DMSO- $\left.d_{6}\right): \delta_{\mathrm{H}}=8.87\left(\mathrm{~d},{ }^{3} J_{\mathrm{HH}}=\right.$ $4.7 \mathrm{~Hz}, 2 \mathrm{H}, \mathrm{H} 2) ; 8.12(\mathrm{~m}, 2 \mathrm{H}, \mathrm{H} 5) ; 8.06\left(\mathrm{dd},{ }^{3} J_{\mathrm{HH}}=7.1 \mathrm{~Hz},{ }^{3} \mathrm{~J}_{\mathrm{HH}}=\right.$ $6.6 \mathrm{~Hz}, 2 \mathrm{H}, \mathrm{H} 4) ; 7.63\left(\mathrm{dd},{ }^{3} J_{\mathrm{HH}}=7.1 \mathrm{~Hz},{ }^{3} J_{\mathrm{HH}}=4.7 \mathrm{~Hz}, 2 \mathrm{H}, \mathrm{H} 3\right)$; $7.06\left(\mathrm{~d},{ }^{3} J_{\mathrm{HH}}=8.5 \mathrm{~Hz}, 4 \mathrm{H}, \mathrm{H6}\right), 7.00\left(\mathrm{~d},{ }^{3} J_{\mathrm{HH}}=8.5 \mathrm{~Hz}, 4 \mathrm{H}, \mathrm{H} 7\right)$; $5.11\left(\mathrm{~d},{ }^{2} J_{\mathrm{HH}}=15.7 \mathrm{~Hz}, 4 \mathrm{H}, \mathrm{H} 1\right) ; 4.90\left(\mathrm{~d},{ }^{2} J_{\mathrm{HH}}=15.7 \mathrm{~Hz}, 4 \mathrm{H}, \mathrm{H} 1\right)$; $2.20\left(\mathrm{~s}, 6 \mathrm{H}, \mathrm{CH}_{3}\right) . \mathrm{NMR}{ }^{31} \mathrm{P}\left\{{ }^{1} \mathrm{H}\right\}\left(162 \mathrm{MHz}, 303 \mathrm{~K}, \mathrm{DMSO}-d_{6}\right)$ : $\delta_{\mathrm{P}}=-0.45 \mathrm{ppm}$.

$N$-Methylpyridinium iodide (NMePyI) and $N, N, N$-trimethylanilinium iodide (TMAI) were synthesized by the interaction of pyridine or aniline with methyl iodide according to the approach described in ref. 31.

$N$-Methylpyridinium tetrafluoroborate $\left(\mathrm{NMePyBF}_{4}\right)$. To a solution of $N$-methylpyridinium iodide $(100 \mathrm{mg}, 45 \mathrm{mmol})$ in
DMF (5 ml) a suspension of silver(I) tetrafluoroborate $(88 \mathrm{mg}$, $45 \mathrm{mmol}$ ) in DMF was added. The reaction mixture was stirred for $1 \mathrm{~h}$. After the yellow precipitate of AgI formed the DMF filtrate was filtered. The precipitate was washed with DMF and dichloromethane 2 times. The combined filtrates were evaporated and dried under vacuum. The yield, $77 \mathrm{mg}(95 \%)$. NMR ${ }^{1} \mathrm{H}$ (400 MHz, $303 \mathrm{~K}, \mathrm{CD}_{2} \mathrm{Cl}_{2}$ ): 8.75 (d, ${ }^{3} \mathrm{JHH}_{\mathrm{HH}} 5.71 \mathrm{~Hz}, 2 \mathrm{H}, \mathrm{o}-\mathrm{H}(\mathrm{Py})$ ), 8.48 (tr, $\left.1 \mathrm{H},{ }^{3} \mathrm{~J}_{\mathrm{HH}} 7.9 \mathrm{~Hz}, \mathrm{p}-\mathrm{H}(\mathrm{Py})\right), 8.05$ (br.dd, ${ }^{3} \mathrm{JHH}_{\mathrm{HH}}+{ }^{3} \mathrm{JHH}_{\mathrm{HH}} 12.8 \mathrm{~Hz}$, $2 \mathrm{H}, \mathrm{m}-\mathrm{H}(\mathrm{Py})), 4.47$ (s, 3H, H(Me)). The X-ray fluorescence spectral analysis was applied to confirm the purity of the compound.

\section{Methods}

Crystallographic data for $(\mathrm{AuCl})_{2} \mathrm{~L} \cdot \mathrm{AN}$ and $(\mathrm{AuCl})_{2} \mathrm{~L} \cdot \mathrm{DMSO}$. Single crystals suitable for X-ray analysis were grown from DMSO and AN solutions. Crystal structures of $(\mathrm{AuCl})_{2} \mathrm{~L} \cdot \mathrm{AN}$ and $(\mathrm{AuCl})_{2} \mathrm{~L} \cdot \mathrm{DMSO}$ were determined by the means of single crystal X-ray diffraction analysis.

Data of $(\mathrm{AuCl})_{2} \mathrm{~L} \cdot \mathrm{AN}$ and $(\mathrm{AuCl})_{2} \mathrm{~L} \cdot \mathrm{DMSO}$ were collected on a Bruker Smart Apex II CCD diffractometer using graphite monochromated $\operatorname{MoK} \alpha(\lambda=0.71073 \AA)$ radiation and $\omega$-scan rotation. Data collection images were indexed, integrated, and scaled using the APEX2 data reduction package ${ }^{32}$ and corrected for absorption using SADABS. ${ }^{33}$ The structure was solved by direct methods and refined using the SHELX program. ${ }^{34}$ All nonhydrogen atoms were refined anisotropically. $\mathrm{H}$ atoms were calculated on idealized positions and refined as riding atoms. The inter- and intramolecular short contacts were evaluated by PLATON. ${ }^{35}$

Crystal data and experimental details are given in Table S1 in the ESI. $\dagger$ CCDC 1495007 and $1495008\left((\mathrm{AuCl})_{2} \mathrm{~L} \cdot \mathrm{DMSO}\right.$ and $(\mathrm{AuCl})_{2} \mathrm{~L} \cdot \mathrm{AN}$ respectively).

Luminescence spectra. The steady-state luminescence spectra were recorded on a spectrofluorometer FL3-221-NIR (Jobin Yvon) with a SPEX FL-1042 phosphorimeter in $10 \mathrm{~mm}$ quartz cuvettes. Excitation of samples was performed at $340 \mathrm{~nm}$. Excitation spectra were obtained for an emission wavelength of $500 \mathrm{~nm}$ with a $6 \mathrm{~nm}$ slit width for both excitation and emission.

ESI measurements. ESI measurements were performed using an AmaZon X ion trap mass spectrometer in positive mode.

UV-VIS spectra. UV-VIS spectra were recorded on a Lambda 35 spectrophotometer (Perkin-Elmer) in $10 \mathrm{~mm}$ quartz cuvettes.

NMR spectra. ${ }^{1} \mathrm{H}$ NMR $(400 \mathrm{MHz})$ and ${ }^{31} \mathrm{P}$ NMR $(162 \mathrm{MHz})$ spectra were recorded using a Bruker Avance-400 spectrometer. Chemical shifts are reported in ppm relative to $\mathrm{SiMe}_{4}$ $\left({ }^{1} \mathrm{H}\right.$; internal standard) and $85 \% \mathrm{H}_{3} \mathrm{PO}_{4}$ (aq) $\left({ }^{31} \mathrm{P}\right.$; external standard). Coupling constants $(J)$ are reported in $\mathrm{Hz}$.

$\mathrm{X}$-ray fluorescence. $\mathrm{X}$-ray fluorescence spectra were obtained using an energy-dispersive X-ray spectrometer EDX 800HS2 (Shimadzu).

DFT computations. All calculations were performed with the ORCA program of version $3.0 .^{36}$ The hybrid PBE0 functional ${ }^{37}$ and the Ahlrichs' triple- $\zeta$ def-TZVP ${ }^{38}$ AO basis set were used for optimization of all structures. Harmonic frequencies were calculated on these geometries (by PBE0) in order to verify these as minima. In all geometry optimizations the D3 approach ${ }^{39}$ to describe the London dispersion interactions together with the 
Becke-Johnson (BJ) damping function ${ }^{40-42}$ was employed as implemented in the ORCA program.

\section{Results and discussion}

\section{Synthesis of crystalline solvates of $(\mathrm{AuCl})_{2} \mathrm{~L}$ and their X-ray structure}

Taking into account previously reported "host-guest" binding of $(\mathrm{AuCl})_{2} \mathrm{~L}$ with acetone molecules in the crystalline solvates ${ }^{28}$ binding modes with other solvents are of particular importance. Solvents DMSO and DMF are widely used dipolar aprotic solvents with two methyl groups and oxygen atoms on their positive and negative sides respectively, which make them structurally analogous to acetone. AN with nitrogen atoms at the negative side and the only methyl group at the positive side exemplifies another structural type of dipolar aprotic solvents. Thus, the aim of this issue is to reveal binding modes of the above-mentioned solvent molecules with $(\mathrm{AuCl})_{2} \mathrm{~L}$.

The crystal samples have been grown from solutions of $(\mathrm{AuCl})_{2} \mathrm{~L}$ in these solvents. The crystals suitable for singlecrystal X-ray analysis were obtained for the solvates with DMSO and AN, while not for the solvates with DMF. The X-ray data (Fig. 1) reveal "chair-chair" conformation adopted by the ligand in $(\mathrm{AuCl})_{2} \mathrm{~L}$, which is a basis for the cavity-like structure built from two $\mathrm{Au}-\mathrm{Cl}$ bonds and two tolyl moieties. This cavitylike structure provides the binding site for DMSO and AN solvent molecules due to electrostatic and $\mathrm{CH}-\pi$ interactions (vide infra) between "host" and "guest" molecules, although the binding modes are different (Fig. 1a and b). Methyl groups of AN form two short contacts with "upper" sites of $(\mathrm{AuCl})_{2} \mathrm{~L}$ : $\mathrm{C}-\mathrm{H} \cdots \mathrm{Cl}-\mathrm{Au}(\mathrm{C} \cdots \mathrm{Cl}=3.54 \AA$ and $3.55 \AA$ ) and one $\mathrm{C}-\mathrm{H} \cdots$ tolyl contact (distance between the nearest $\mathrm{H}$ atom of $\mathrm{AN}$ and the tolyl plane is $2.86 \AA$ ) (Fig. 1b), while two methyl groups of DMSO participate in the binding with the "upper site" of $(\mathrm{AuCl})_{2} \mathrm{~L}$ (Fig. 1a). In particular, there are four $\mathrm{C}-\mathrm{H} \cdots \mathrm{Cl}-\mathrm{Au}$ binding links between DMSO and $(\mathrm{AuCl})_{2} \mathrm{~L}$ (with $\mathrm{C} \cdots \mathrm{Cl}$ distances between 3.66 and $3.88 \AA$ ) and two $\mathrm{C}-\mathrm{H}$ - . tolyl links with two tolyl groups (distance between the nearest $\mathrm{H}$ atom of DMSO and the tolyl plane is $2.94 \AA$ ). Comparison of the obtained results (Fig. 1a) with the X-ray data for $(\mathrm{AuCl})_{2} \mathrm{~L}$-acetone crystalline solvate ${ }^{28}$ points to the similarity in the binding modes of $(\mathrm{AuCl})_{2} \mathrm{~L}$ with DMSO and acetone, while AN exemplifies another type of "host-guest" binding.

Moreover, the solvent molecules are bound with both "upper" and "lower" sites of the complex molecule, thus linking the complexes into the chain-like supramolecular packing (Fig. S1 and S2 in the ESI $\dagger$ ). Fig. 1a illustrates the binding mode of DMSO molecules at the "lower" site of the complex through four $\mathrm{CH}_{2} \cdots \mathrm{O}=\mathrm{S}$ short contacts $(\mathrm{H} \cdots \mathrm{O}$ distances are in the range of 2.44-2.46 $\AA$ ), while rather loose and asymmetric binding with the "lower" site is revealed for AN molecules (Fig. 1b). The latter is close just to one side of the PNNP ligand (corresponding $\mathrm{H} \cdots \mathrm{N}$ distances are 2.49 and $2.53 \AA$ ), whereas $\mathrm{H} \cdots \mathrm{N}$ distances with other two methylene groups are 3.26 and 3.44 Å. Thus, $(\mathrm{AuCl})_{2} \mathrm{~L}$ can be regarded as a "host" molecule

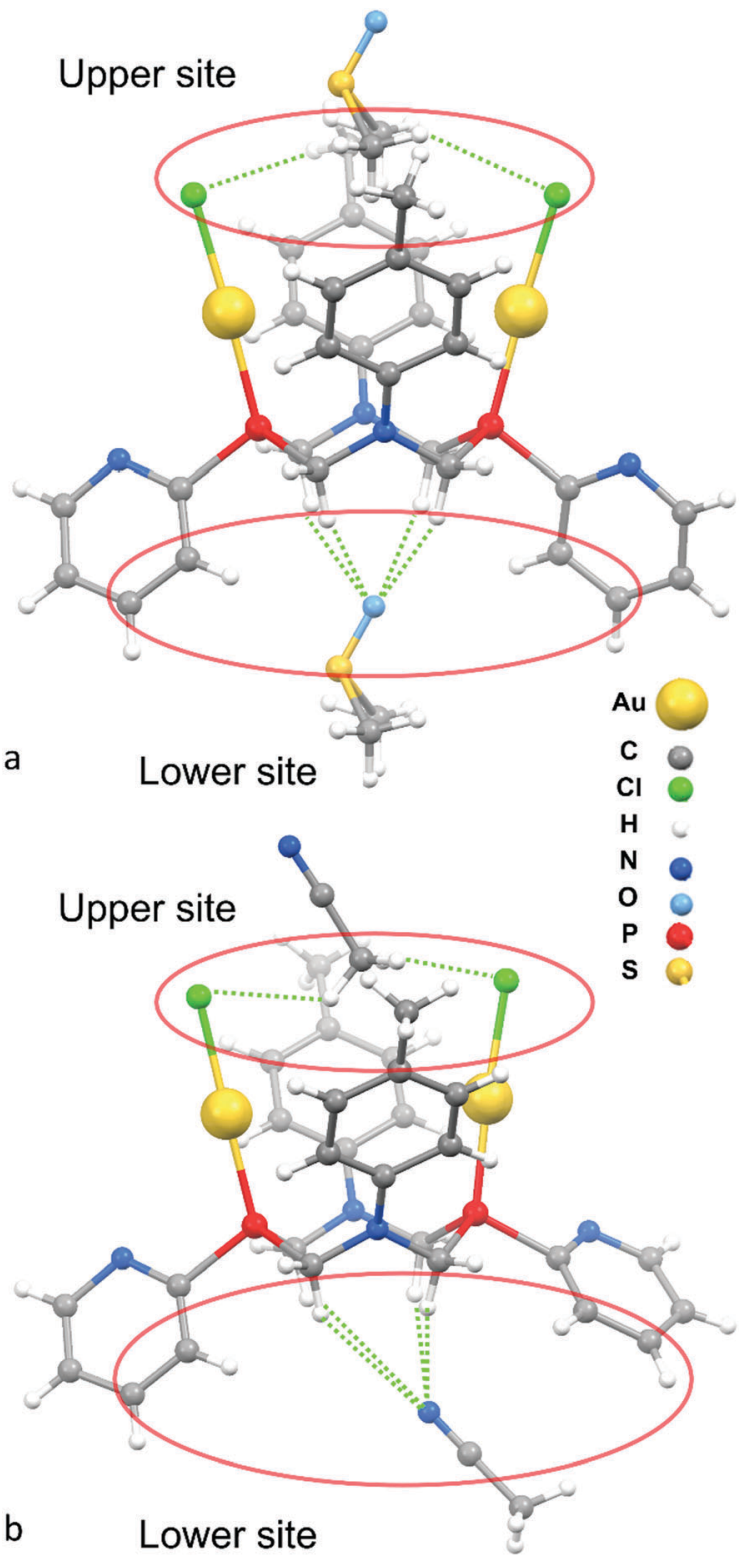

Fig. 1 X-Ray data of single crystals grown from DMSO (a) and AN (b) solutions of $(\mathrm{AuCl})_{2} \mathrm{~L}$.

with two binding sites, which will be further designated as "upper" and "lower" ones. The intramolecular $\mathrm{Au}-\mathrm{Au}$ distances are greater than $5 \AA$ in both $(\mathrm{AuCl})_{2} \mathrm{~L} \cdot 2 \mathrm{AN}$ and $(\mathrm{AuCl})_{2} \mathrm{~L} \cdot 2 \mathrm{DMSO}$, which excludes an effect of aurophilic interactions on the spectral behavior of $(\mathrm{AuCl})_{2} \mathrm{~L}$ in $\mathrm{AN}$ and DMSO.

The above-mentioned differences in structures of crystalline solvates $(\mathrm{AuCl})_{2} \mathrm{~L} \cdot \mathrm{AN}$ and $(\mathrm{AuCl})_{2} \mathrm{~L} \cdot \mathrm{DMSO}$ are reproduced by quantum chemical optimizations of the corresponding isolated species, (Fig. S3 and S4 in the ESI, $\uparrow$ respectively). The optimized structures correspond to minima of the potential energy surface, which means that such entities do not result from solid state effects. The same is true for isolated solvates of $(\mathrm{AuCl})_{2} \mathrm{~L}$ with two acetone and two DMF molecules (Fig. S5 and S6 in the ESI, $\dagger$ respectively). This suggests the existence of the similar structures not only in crystals, but also in solutions. The partial atomic 
charge distribution on the "host" and "guest" molecules (Fig. S5 in the ESI $\dagger$ ) indicates that the "host-guest" formation is, most probably, driven by Coulomb attraction of partial atomic charges of opposite sign on methyl groups of solvent molecules and $\mathrm{Cl}$ atoms of $(\mathrm{AuCl})_{2} \mathrm{~L}$, in the case of binding via "upper" sites of $(\mathrm{AuCl})_{2} \mathrm{~L}$. This fact suggests the nucleophilicity of the "upper" site. The binding via "lower" sites of $(\mathrm{AuCl})_{2} \mathrm{~L}$ is contributed by Coulomb attraction of oxygen atoms of acetone, DMSO or DMF molecules with hydrogen atoms of $\mathrm{P}-\mathrm{CH}_{2}-\mathrm{N}$ and pyridyl moieties (Fig. S3-S6 in the ESI $\dagger$ ). Thus, the "lower" site can be considered as the electrophilic one. It should be noted that optimization of isolated $(\mathrm{AuCl})_{2} \mathrm{~L} \cdot 2 \mathrm{AN}$ and $(\mathrm{AuCl})_{2} \mathrm{~L} \cdot 2 \mathrm{DMSO}$ species reveals the closer binding of the DMSO molecule at the "lower" side of the complex through $\mathrm{CH}_{2} \cdots \mathrm{O}=\mathrm{S}$ interactions (the shortest $\mathrm{H} \cdots \mathrm{O}$ distance is $2.28 \AA$ ) relative to rather loose binding of the AN molecule at the same "lower" side of the complex (the shortest $\mathrm{H} \cdots \mathrm{N}$ distance is $2.46 \AA$ ). Different polarities of the DMSO and AN and different nature of hydrogen bonding acceptor atoms ( $\mathrm{O}$ versus $\mathrm{N}$ ) are the reasons for the observed difference between the "host-guest" binding of DMSO and AN with $(\mathrm{AuCl})_{2} \mathrm{~L}$.

\section{Photophysical properties of $(\mathrm{AuCl})_{2} \mathrm{~L}$ in different solvents}

Experimental and quantum chemically simulated absorption spectra of $(\mathrm{AuCl})_{2} \mathrm{~L}$ and $\mathrm{L}$ are presented in Fig. 2 . Both the wavelengths and the large extinction coefficients of the dominating bands are typical for ligand-centered $\pi-\pi^{*}$ transitions. According to our computations, as well as calculations reported earlier, ${ }^{28}$ the band at $315 \mathrm{~nm}$ in the ligand spectrum is associated with charge transfer from para-tolyl to pyridyl moieties (intraligand charge transfer, ILCT). In the spectrum of $(\mathrm{AuCl})_{2} \mathrm{~L}$ the low energy band is contributed by both ILCT and metal-to-ligand charge-transfer (MLCT) transitions mixed with halogen-to-ligand charge-transfer (XLCT) transitions and therefore belongs both to ILCT and to $(\mathrm{X}+\mathrm{M}) \mathrm{LCT}$ states (see the HOMO and the LUMO in Fig. 2). High-energy bands at $260 \mathrm{~nm}$

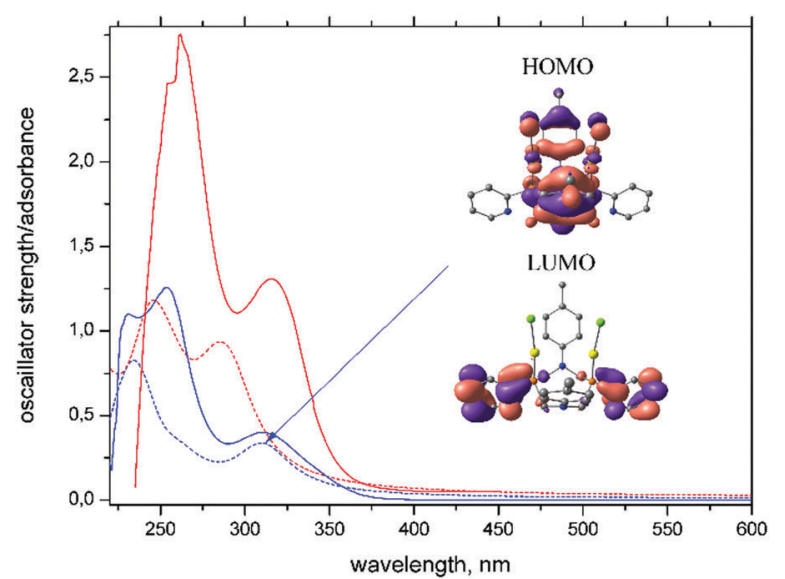

Fig. 2 Experimental (solid lines) and calculated (dashed lines) absorption spectra of solutions of ligand $\mathrm{L}$ (red lines) and complex $(\mathrm{AuCl})_{2} \mathrm{~L}$ (blue lines) in $\mathrm{AN}$. $\mathrm{C}\left((\mathrm{AuCl})_{2} \mathrm{~L}\right)=\mathrm{C}(\mathrm{L})=0.025 \mathrm{mM}$. Vertical dashed lines correspond to computed transitions between highest occupied (HOMO) and lowest unoccupied molecular orbitals (LUMO) of $(\mathrm{AuCl})_{2} \mathrm{~L}$, shown in insets.
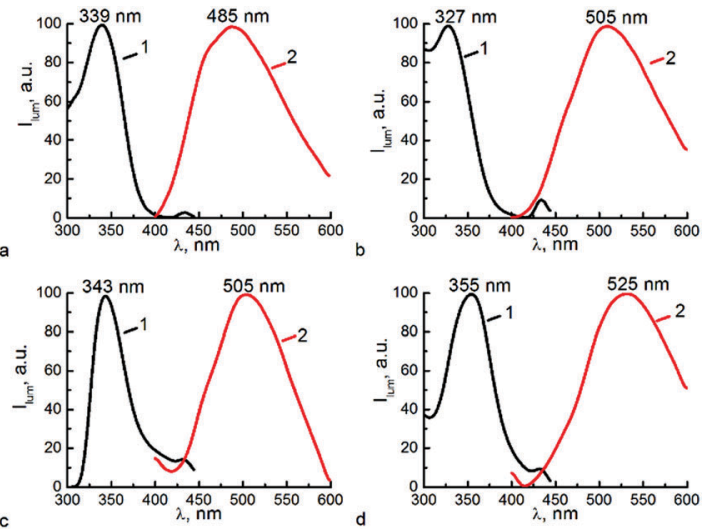

Fig. 3 Normalized excitation $\left(1, \lambda_{\mathrm{em}}=500 \mathrm{~nm}\right)$ and emission $\left(2, \lambda_{\mathrm{ex}}=\right.$ $340 \mathrm{~nm}$ ) spectra of solutions of $(\mathrm{AuCl})_{2} \mathrm{~L}$ in DCM (a), AN (b), acetone (c) and DMSO (d). $\mathrm{C}\left((\mathrm{AuCl})_{2} \mathrm{~L}\right)=0.2 \mathrm{mM}$.

are due to $\pi-\pi^{*}$ transitions within pyridyl and para-tolyl moieties of the ligand.

Intraligand transitions are very common sources of emission for $\mathrm{Au}(\mathrm{I})$ complexes, ${ }^{43}$ although metal-centered transitions, and charge transfer transitions involving either a metal to ligand or a ligand to metal transfer are worth noting as other possible sources of luminescence. ${ }^{18,44}$ Emission and corresponding excitation spectra of complex $(\mathrm{AuCl})_{2} \mathrm{~L}$ in various solvents are presented in Fig. 3. Comparison of the spectral patterns revealed for $(\mathrm{AuCl})_{2} \mathrm{~L}$ and $\mathrm{L}$ (Fig. S7 in the ESI $\dagger$ ) indicates a similarity in their spectral behavior, which points to intraligand transitions as the main source of luminescence of $(\mathrm{AuCl})_{2} \mathrm{~L}$. Similarity of the luminescence in the crystalline state and solutions of $(\mathrm{AuCl})_{2} \mathrm{~L}$ suggests that the molecular structure has a greater impact on the photophysical properties compared to a crystal packing.

Photostability of $\mathrm{Au}(\mathrm{I})$ complexes in solutions is of great importance in the viewpoint of their spectral behavior, since photodegradation is a factor for an instability of $\mathrm{Au}(\mathrm{I})$ complexes. ${ }^{45} \mathrm{NMR}$ spectral data indicate stability of $(\mathrm{AuCl})_{2} \mathrm{~L}$ in DMSO solutions (Fig. S8 in the ESI $\dagger$ ). Nevertheless, the repeated recording of the $(\mathrm{AuCl})_{2} \mathrm{~L}$ emission spectra in organic solutions demonstrates the steadily decreasing intensity of the main emission band and parallel enhancement of emission at 400-450 $\mathrm{nm}$. This tendency is exemplified by the spectra of DMSO solution in Fig. S9 (ESI $\dagger$ ), where the time-induced spectral changes are most pronounced due to the oxidation of the ligand. To avoid this impediment, spectral measurements were performed within several minutes after sample preparation. The deaeration of the solutions results in the enhancement of the emission (Fig. S10 in the ESI $\dagger$ ). The dynamic quenching by oxygen points to the triplet excited state as the reason for radiation decay of $(\mathrm{AuCl})_{2} \mathrm{~L}$ in solutions. ${ }^{46}$ Nevertheless, the spectra presented herein were recorded without deaeration in order to reveal the capacity of $(\mathrm{AuCl})_{2} \mathrm{~L}$ to stimuli response under ambient conditions.

Luminescence spectra of $(\mathrm{AuCl})_{2} \mathrm{~L}$ in acetone solutions are red shifted relative to those in DCM solutions (Fig. 3). A similar trend is reported for the crystalline solvates grown from acetone 
and DCM solutions. ${ }^{28}$ The correlation between emission wavelengths in solutions and the solid state suggests similarity in host-guest binding of $(\mathrm{AuCl})_{2} \mathrm{~L}$ with the solvent molecules in solutions and in the crystalline solvates. Thus, the "host-guest" binding mode is the most probable reason for the luminescence solvatochromism of $(\mathrm{AuCl})_{2} \mathrm{~L}$.

Analysis of the binding modes in crystalline solvates of $(\mathrm{AuCl})_{2} \mathrm{~L}$ with DMSO and AN (vide supra) as well as with acetone ${ }^{28}$ reveals certain differences between them. Syn-arrangement of the nitrogen lone pairs of the pyridyl moieties and $\mathrm{P}-\mathrm{Au}$ bonds of $(\mathrm{AuCl})_{2} \mathrm{~L}$ is found in the case of "lower" site binding of acetone ${ }^{28}$ and DMSO molecules (Fig. 1a). Loose contact of AN with the "lower" site of $(\mathrm{AuCl})_{2} \mathrm{~L}$ results in the syn-orientation of only one nitrogen lone pair relative to the $\mathrm{P}-\mathrm{Au}$ bond, while anti-orientation is adopted by the lone pair of another pyridyl moiety (Fig. 1b). Only antiorientations are found for the both pyridyl moieties in the case of the crystalline solvates with one acetone molecule bound via "upper" sites of $(\mathrm{AuCl})_{2} \mathrm{~L}^{28} \mathrm{~A}$ comparison of the reported ${ }^{28}$ emission spectra of the latter crystalline solvate and of the solvate with two acetone molecules bound via both sides of $(\mathrm{AuCl})_{2} \mathrm{~L}$ points to a stronger effect of the solvent molecule bound with "lower" sites on the luminescence of $(\mathrm{AuCl})_{2} \mathrm{~L}$. Thus, the stronger impact of binding via the "lower" binding site on the luminescence solvatochromism of $(\mathrm{AuCl})_{2} \mathrm{~L}$ suggests that mutual arrangement of pyridyl moieties and $\mathrm{P}-\mathrm{Au}$ bonds of $(\mathrm{AuCl})_{2} \mathrm{~L}$ is of importance for the luminescence of this complex.

The quantum chemical calculations confirm the impact of the conformation of pyridyl moieties on the wavelength of $(\mathrm{AuCl})_{2} \mathrm{~L}$ emission. Optimization of various conformers of $(\mathrm{AuCl})_{2} \mathrm{~L}$ immersed in acetone treated as polarisable continuum ${ }^{47}$ produced two minima on the potential energy surface (Fig. 4 a and b). Conformer a is less energetically stable than conformer $b$ by

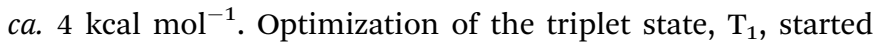
with geometry of the ground state $\left(\mathrm{S}_{0}\right)$ of syn,syn-conformer a, resulted in structure $\mathbf{c}$ (Fig. 4) and optimization of the triplet state, $\mathrm{T}_{1}$, started with geometry of the ground state $\left(\mathrm{S}_{0}\right)$ of
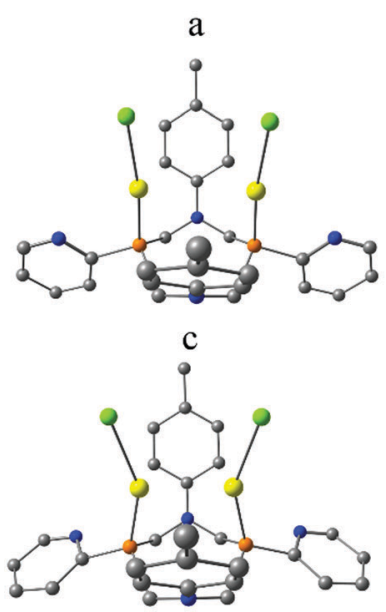

Fig. 4 Optimized ground state $\left(\mathrm{S}_{0}\right)$ structures of $(\mathrm{AuCl})_{2} \mathrm{~L}$ with (a) syn,synand (b) anti,anti-conformations of pyridyl moieties and the corresponding optimized structures of the excited triplet state $T_{1}$ of $(A u C l)_{2} L(c)$ and (d). anti,anti-conformer $\mathbf{b}$, resulted in structure $\mathbf{d}$ (Fig. 4). The energy of $\mathrm{T}_{1}$ (d) is higher by $c a .8 \mathrm{kcal} \mathrm{mol}^{-1}$ compared to $\mathrm{T}_{1}$ (c). The TDDFT calculations predict emission wavelengths of $377 \mathrm{~nm}$ for $\mathrm{T}_{1}(\mathbf{d})$ and $439 \mathrm{~nm}$ for $\mathrm{T}_{1}(\mathbf{c})$. This red shift, resulting from the change of conformation of pyridyl moieties, qualitatively corresponds to the experimental data. Emission of $(\mathrm{AuCl})_{2} \mathrm{~L}$ in DCM solutions, where pyridyl moieties are free to adopt more energetically stable anti, anti-conformation, is observed at $485 \mathrm{~nm}$. In acetone and DMSO solutions, where solvent molecules bind the complex from its "lower" side and force pyridyl moieties to adopt syn,syn-conformation a, emission is red shifted to 505 and $525 \mathrm{~nm}$, respectively.

\section{Luminescence of $(\mathrm{AuCl})_{2} \mathrm{~L}$ in mixed solvents $\mathrm{AN}-\mathrm{DMF}$, AN-acetone, AN-DMSO}

Non-normalized luminescence spectra of $(\mathrm{AuCl})_{2} \mathrm{~L}$ in different solvents at the same concentration of the complex are different in both intensity and maximum wavelength, which suggests that the luminescence dependence on the mixed solvent composition should be expected. Thus, luminescence measurements were performed for mixed $\mathrm{S}_{1}+\mathrm{S}_{2}$ solutions of $(\mathrm{AuCl})_{2} \mathrm{~L}$, where $S_{2}$ is acetone, DMF or DMSO, $S_{1}$ is AN. The composition of the mixed solvent was varied through the variation of the concentrations, namely $C_{\mathrm{S}_{1}}$ and $C_{\mathrm{S}_{2}}$, while the sum of $C_{\mathrm{S}_{1}}$ and $C_{\mathrm{S}_{2}}$ was kept at the constant level. Fig. $5 \mathrm{a}$ and b exemplify the changes in the emission spectra of $(\mathrm{AuCl})_{2} \mathrm{~L}$ in the mixed solvents AN-DMSO and AN-DMF. The presented spectra (Fig. 5a and b) show that the luminescent solvatochromism of $(\mathrm{AuCl})_{2} \mathrm{~L}$ is manifested by both wavelength and intensity of the emission. In particular, emission of $(\mathrm{AuCl})_{2} \mathrm{~L}$ is more intensive in DMSO and DMF than in AN solutions. Taking into account the similarity of the electronic absorption spectra of $(\mathrm{AuCl})_{2} \mathrm{~L}$ in DMSO, DMF and AN (Fig. S11 in the ESI $\dagger$ ), the above mentioned difference in emission intensity (Fig. 5) points to different quantum yields of $(\mathrm{AuCl})_{2} \mathrm{~L}$ in these solvents. Changes in luminescence of both $\mathrm{L}$ and $(\mathrm{AuCl})_{2} \mathrm{~L}$ upon the variation of the mixed solvent composition are represented in Fig. $5 \mathrm{c}$ by plotting $I / I_{0}$ versus molar fractions $\left(\alpha_{\mathrm{S}_{2}}\right)$ of acetone, DMF or DMSO in their mixture with AN. $\alpha_{\mathrm{S}_{2}}$ is calculated through eqn (1). $I$ and $I_{0}$ are the luminescence intensities of $(\mathrm{AuCl})_{2} \mathrm{~L}$ at $500 \mathrm{~nm}$ detected from the emission spectra recorded in the mixed solvent and in AN as a single solvent respectively.

$$
\alpha\left(\mathrm{S}_{2}\right)=C\left(\mathrm{~S}_{2}\right) /\left(C\left(\mathrm{~S}_{1}\right)+C\left(\mathrm{~S}_{2}\right)\right)
$$

Fig. $5 \mathrm{c}$ indicates the insignificant solvatochromism for the ligand, while the increase in $\alpha_{\mathrm{S}_{2}}$ leads to the significant increase of $I / I_{0}$ for $(\mathrm{AuCl})_{2} \mathrm{~L}$, when $\mathrm{S}_{2}$ is DMF and DMSO (Fig. $5 \mathrm{c}$, curves 3 and 4 ), albeit the change of $I / I_{0}$ is less pronounced in the case of acetone (Fig. 5c, curve 2). The nonlinear dependence of $I / I_{0}$ on $\alpha_{\mathrm{S}_{2}}$ with a breakpoint at about $0.5 \alpha_{\mathrm{S}_{2}}$ is observed for the mixed solutions of $(\mathrm{AuCl})_{2} \mathrm{~L}$ (Fig. 5c). Taking into account that the spectral changes (Fig. 5) are greatly affected by a competition between $\mathrm{S}_{1}$ and $\mathrm{S}_{2}$ for the binding with $(\mathrm{AuCl})_{2} \mathrm{~L}$, deviation from the linearity points to the predominant solvation of $(\mathrm{AuCl})_{2} \mathrm{~L}$ by $\mathrm{S}_{2}$ rather than by $\mathrm{AN}$. This fact correlates with the 

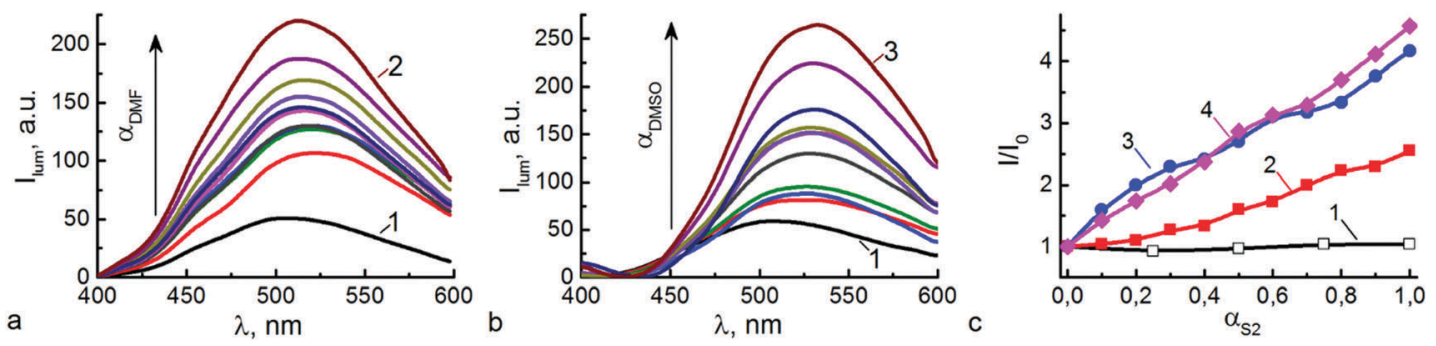

Fig. 5 (a and b) Emission spectra of $(A u C l)_{2} L$ in mixed solvents. $S_{1}=A N, S_{2}=D M F(a) ; S_{1}=A N, S_{2}=D M S O(b) . C\left(S_{1}\right)+C\left(S_{2}\right)=C o n s t . C\left((A u C l)_{2} L\right)=0.2 m M$. $\lambda_{\mathrm{ex}}=340 \mathrm{~nm}$. The spectra designated by $1,2,3$ are recorded in AN, DMF and DMSO correspondingly. (c) $I / I_{0}$ values for ligand $\mathrm{L}(1)$ and $(\mathrm{AuCl})_{2} \mathrm{~L}(2-4)$ versus $\alpha_{\mathrm{S}_{2}}$ in $\mathrm{S}_{1}+\mathrm{S}_{2}$, where $\mathrm{S}_{1}=\mathrm{AN}, \mathrm{S}_{2}=$ acetone $(1,2)$, DMF (3), DMSO (4). $C(\mathrm{~L})=C\left((\mathrm{AuCl})_{2} \mathrm{~L}\right)=0.2 \mathrm{mM} . \lambda_{\mathrm{ex}}=340 \mathrm{~nm}, \lambda_{\mathrm{em}}=500 \mathrm{~nm}$.

above-mentioned difference in the binding modes revealed for the crystalline solvates of $(\mathrm{AuCl})_{2} \mathrm{~L}$ with DMSO and AN.

Significant differences in dipole moments of acetone $(2.88 \mathrm{D})$, DMF (3.82 D) and DMSO (3.96 D) should be responsible for the different host-guest binding mode and binding constant. Moreover, comparison of the dependencies measured for $(\mathrm{AuCl})_{2} \mathrm{~L}$ and $\mathrm{L}$ in the mixed solvents (Fig. 5) points to the impact of $\mathrm{Au}-\mathrm{Cl}$ moieties on the "host-guest" binding of $\left(\mathrm{AuCl}_{2} \mathrm{~L}\right.$ with the solvents. This is the reason for considering two pre-organized $\mathrm{Au}-\mathrm{Cl}$ moieties of $(\mathrm{AuCl})_{2} \mathrm{~L}$ (designated as the "upper" site) as binding sites for positively charged moieties of guest molecules. Although electrostatic attraction is a powerful driving force for the binding via "upper" sites, the greater impact of the "lower" site on luminescence solvatochromism has been indicated above.

\section{Solvent effects on the luminescence response of $(\mathrm{AuCl})_{2} \mathrm{~L}$ to $\mathrm{N}$-methylpyridinium and diphenylketone}

In order to gain deeper insights into the origin of luminescence tuneability of $(\mathrm{AuCl})_{2} \mathrm{~L}$ we have tried to correlate the luminescence response of $(\mathrm{AuCl})_{2} \mathrm{~L}$ to "host-guest" interactions via both "upper" and "lower" binding sites. Moreover, detection of the concentration-dependent luminescence response of $(\mathrm{AuCl})_{2} \mathrm{~L}$ to model substrates in AN, DMF and DMSO solutions is aimed at recognition of solvent effects on the luminescence response. The requirements for the model substrate structure arise from the structural specificity of "upper" and "lower" binding sites.

The presence of two pre-organized $\mathrm{Au}-\mathrm{Cl}$ moieties in the "upper" site of $(\mathrm{AuCl})_{2} \mathrm{~L}$ is the reason for its nucleophilicity. Thus, positively charged $N$-methylpyridinium $\left(\mathrm{NMePy}^{+}\right)$and $N, N, N$-trimethylanilinium $\left(\mathrm{TMA}^{+}\right)$iodides were chosen to reveal the luminescence response to the binding via "upper" sites. The spectra presented in Fig. 6 indicate that the increased concentration of NMePyI in AN, DMSO and DMF solutions induces the changes in the luminescence of $(\mathrm{AuCl})_{2} \mathrm{~L}$. A similar change in the complex luminescence is observed under the increased concentration of TMAI (Fig. S12 in the ESI $\dagger$ ).

The 1:1 binding of $(\mathrm{AuCl})_{2} \mathrm{~L}$ with both cationic guests was confirmed by ESI mass spectrometry. The ESI-MS spectra of the solutions containing $(\mathrm{AuCl})_{2} \mathrm{~L}$ and NMePyI, as well as $(\mathrm{AuCl})_{2} \mathrm{~L}$ and TMAI are presented in Fig. 7. The peaks at $m / z^{+} 1226.0$ and 1268.1 are revealed in the spectra measured in AN solutions of $(\mathrm{AuCl})_{2} \mathrm{~L}$ in the presence of $\mathrm{NMePy}^{+}$(Fig. 7a) and $\mathrm{TMA}^{+}$(Fig. 7b).
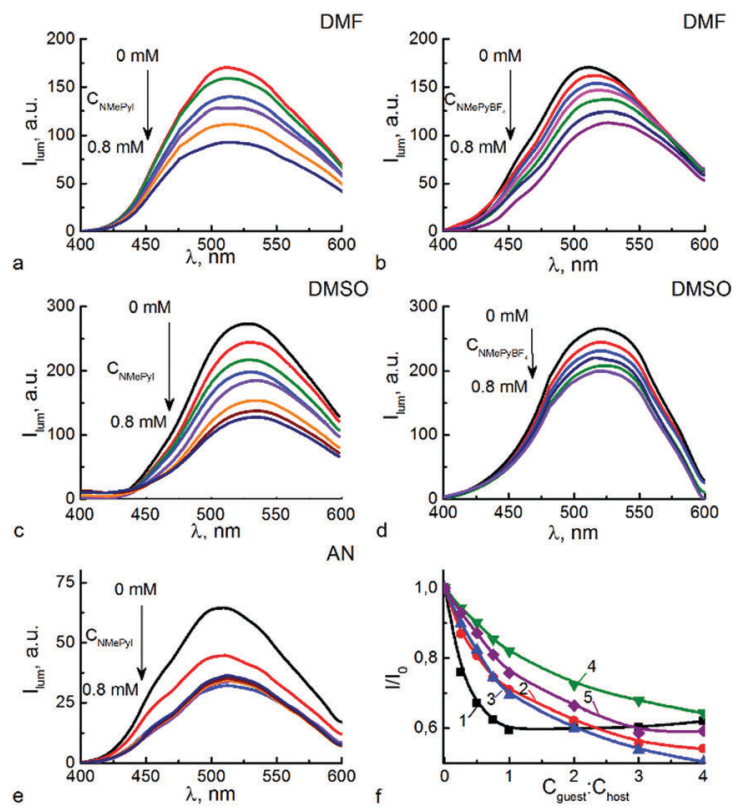

Fig. 6 (a-e) Emission spectra of $(\mathrm{AuCl})_{2} \mathrm{~L}(0.2 \mathrm{mM})$ at various concentrations $\left(0-0.8 \mathrm{mM}\right.$ ) of NMePyl (a, c and e) and $\mathrm{NMePyBF}_{4}(\mathrm{~b}$ and $d)$ in DMF ( $a$ and b), DMSO (c and d) and AN (e). (f) $I / l_{0}$ of $\left(\mathrm{AuCl}_{2} \mathrm{~L}\right.$ (host) versus guest: host concentration ratio in $\operatorname{AN}(1), \operatorname{DMF}(2,4)$ and $\operatorname{DMSO}(3,5)$ solutions, where guests are NMePyl (1-3), NMePyBF $4(4,5) . \lambda_{e x}=340 \mathrm{~nm}, \lambda_{\mathrm{em}}=500 \mathrm{~nm}$.

These peaks are assigned to $\left[(\mathrm{AuI})_{2} \mathrm{~L}(\mathrm{NMePy})\right]^{+}$and $\left[(\mathrm{AuI})_{2} \mathrm{~L}(\mathrm{TMA})\right]^{+}$ respectively, where both chlorides in the complex are substituted by iodides. This result points to the possibility of $\mathrm{Au}-\mathrm{Cl}$ group dissociation with further chloride substitution by iodides arisen from NMePyI and TMAI under the experimental conditions. The easy dissociation of $\mathrm{Au}-\mathrm{Cl}$ bonds is confirmed by the peak at $\mathrm{m} / \mathrm{z}^{2+}$ 681.2 assignable to $\left[\mathrm{Au}_{2} \mathrm{~L}_{2}\right]^{2+}$, where both $\mathrm{Au}-\mathrm{Cl}$ are dissociated. Moreover, the peak at $m / z^{+} 1005.0$ assigned to $\left[(\mathrm{AuI})_{2} \mathrm{~L}\right]^{+}$with $\mathrm{Au}-\mathrm{I}$ instead of $\mathrm{Au}-\mathrm{Cl}$ also results from the dissociation followed by the substitution. The isotopic patterns for all peaks are in good agreement with the predicted isotopic distribution patterns.

The above-mentioned results confirm the binding of positively charged guests exemplified by organic cations via "upper" binding sites of $(\mathrm{AuCl})_{2} \mathrm{~L}$, although point to a possibility of AuCl-to-AuI substitution. The anion substitution can be one more reason for the observed spectral changes (Fig. 6). The similar luminescence measurements were performed at various concentrations 


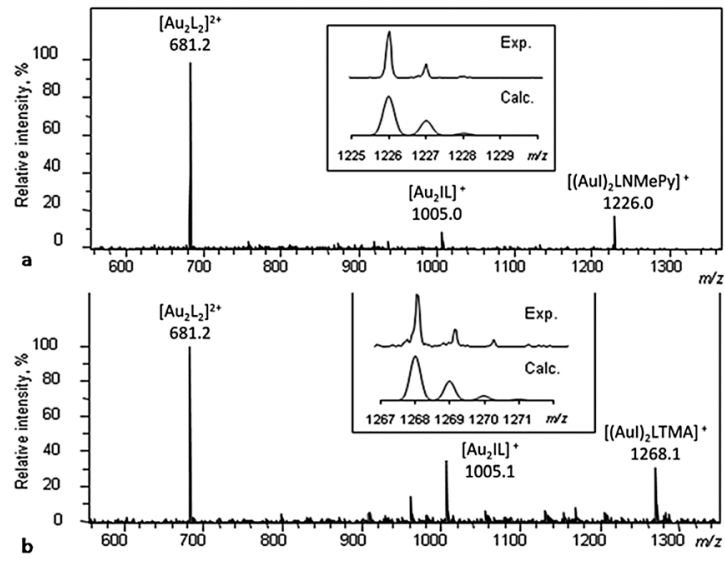

Fig. 7 ESI mass spectra of AN solution containing $(\mathrm{AuCl})_{2} \mathrm{~L}$, NMePyl (a) and TMAI (b). Insets represent isotopic distribution patterns.

of $\mathrm{NMePyBF}_{4}$ in order to separate the influence of the "hostguest" binding from the anion exchange effect. Fig. $6 \mathrm{~b}$ and $\mathrm{d}$ show the spectral changes induced by $\mathrm{NMePyBF}_{4}$ in $\mathrm{DMF}$ and DMSO. The insufficient solubility of $\mathrm{NMePyBF}_{4}$ in AN restricts the performance of the similar measurements in AN. The results (Fig. 6a-d) indicate that the difference between the substrates with iodide and the poor coordinating tetrafluoroborate as counter-ions is not dramatic. In particular, NMePyI induces somewhat greater quenching effect compared to $\mathrm{NMePyBF}_{4}$. (Fig. 6a-d). Thus, the binding of $(\mathrm{AuCl})_{2} \mathrm{~L}$ with $\mathrm{N}$-methylpyridinium cation mainly contributes to the observed spectral changes of the complex, although the anion exchange effect on the complex luminescence cannot be excluded. The similar counter-ion effect is rather anticipated for TMAI versus $\mathrm{TMABF}_{4}$.

Quantitative analysis of the substrate-induced spectral changes of $(\mathrm{AuCl})_{2} \mathrm{~L}$ was performed through plotting of $I / I_{0}$ (where $I_{0}$ and $I$ are intensities at $500 \mathrm{~nm}$ measured in the initial solution of $(\mathrm{AuCl})_{2} \mathrm{~L}$ and after the addition of the guest, respectively) versus concentration of the salts (NMePyI, $\mathrm{NMePyBF}_{4}$ and TMAI) (Fig. $6 \mathrm{f}$ and Fig. S12d in the ESI $\dagger$ ). The plotted dependencies reveal the difference between the solvents. In particular, $I / I_{0}$ values tend to gradually decrease with the growth of NMePyI, $\mathrm{NMePyBF}_{4}$ and TMAI concentrations in DMF and DMSO, while the sharp decrease with the subsequent saturation is observed in AN for NMePyI and TMAI. The breakpoints at a 1:1 (guest: host) concentration ratio are revealed for NMePyI and TMAI in AN (Fig. $6 \mathrm{f}$ and Fig. S12d in the ESI†). This fact points to $1: 1$ "host-guest" complex formation of $(\mathrm{AuCl})_{2} \mathrm{~L}$ with both the guests.

The impact of the "lower" site on tuneability of $(\mathrm{AuCl})_{2} \mathrm{~L}$ luminescence can be revealed by means of the concentrationdependent effect of model substrates on the luminescence of $(\mathrm{AuCl})_{2} \mathrm{~L}$. Diphenylketone (DPK) was chosen as the substrate for preferable binding via "lower" binding sites, since the bulky phenyl substituents provide poor structural fitting to "upper" binding sites. Fig. 8 shows emission spectra recorded at increasing concentrations of DPK in DMF, DMSO and AN solutions indicating both the DPK-induced red shift and the decrease of the emission intensity. These changes (Fig. 8) are
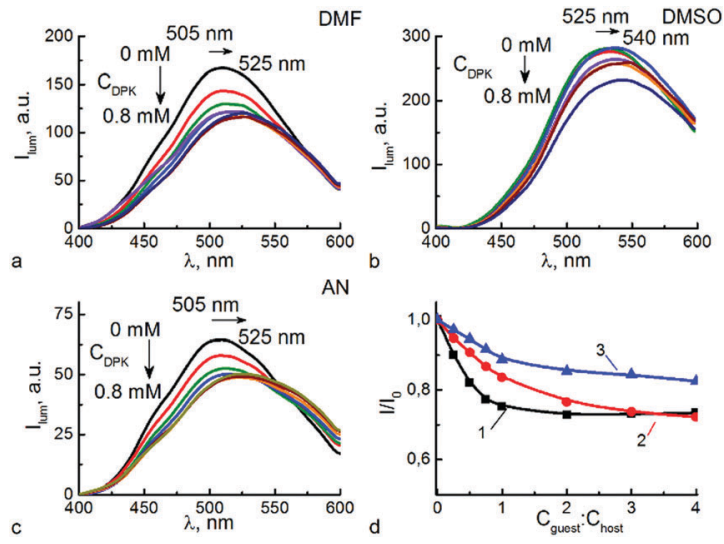

Fig. $8(\mathrm{a}-\mathrm{c})$ Emission spectra of $(\mathrm{AuCl})_{2} \mathrm{~L}(0.2 \mathrm{mM})$ at various concentrations (0-0.8 mM) of DPK in DMF (a), DMSO (b) and AN (c). Horizontal arrows designate the red shifting of the emission band. (d) $I / I_{0}$ of $\left(\mathrm{AuCl}_{2} \mathrm{~L}\right.$ (host) versus DPK : host concentration ratio in AN (1), DMF (2) and DMSO (3) solutions. $\lambda_{\mathrm{ex}}=340 \mathrm{~nm}, \lambda_{\mathrm{em}}=500 \mathrm{~nm}$.

similar to those resulting from the cationic guests (Fig. 6), although some difference is worth noting. In particular, the decrease in emission intensity is less pronounced for DPK versus the cationic guests. Nevertheless, $I / I_{0}$ values $\left(I_{0}\right.$ and $I$ are intensities at $500 \mathrm{~nm}$ measured in the initial solution of $\left(\mathrm{AuCl}_{2} \mathrm{~L}\right.$ and after the addition of the guest, respectively) plotted versus guest:host concentration reveal the impact of the solvent nature on the guest-induced response of $(\mathrm{AuCl})_{2} \mathrm{~L}$ (Fig. 8d). Changes in $I / I_{0}$ values are less pronounced in DMF and DMSO (Fig. 8d) than in AN which is similar to the cationic guest effect (Fig. 6f). It is also worth noting that the increase in DPK concentration results in a more pronounced red shift of the emission band than the cationic guests (Fig. 6, 8 and Fig. S12 in the ESI $\dagger$ ). This tendency confirms the effect of the substrate binding via "lower" sites of $(\mathrm{AuCl})_{2} \mathrm{~L}$ on the excited state energy.

The dependencies presented in Fig. 6 and Fig. S12 (in the ESI $\dagger$ ) and 8 indicate the competition between the guest and solvent molecules in DMF and DMSO solutions. The guest-induced spectral changes of $(\mathrm{AuCl})_{2} \mathrm{~L}$ occur in the narrow concentration range with the breakpoint at a 1:1 guest:host concentration ratio in AN solutions. This tendency points to more efficient "host-guest" binding of $\left(\mathrm{AuCl}_{2} \mathrm{~L}\right.$ with the substrate in $\mathrm{AN}$ solutions, which in turn can be explained by dominating the substrate in competition with the solvent molecules for binding with $(\mathrm{AuCl})_{2} \mathrm{~L}$. The difference in the concentration dependent luminescence response of $\left(\mathrm{AuCl}_{2} \mathrm{~L}\right.$ in AN and DMF solutions to the guests (DPK, NMePyI, $\mathrm{NMePyBF}_{4}$ and TMAI) reveals AN as a more convenient solvent for capacity of $(\mathrm{AuCl})_{2} \mathrm{~L}$ to the luminescence stimuli response, while the solvation of $(\mathrm{AuCl})_{2} \mathrm{~L}$ in DMF and DMSO solutions through "lower" and "upper" binding sites is the reason for the less significant capacity for the stimuli response of $(\mathrm{AuCl})_{2} \mathrm{~L}$ in DMF (DMSO) versus $\mathrm{AN}$ solutions.

\section{Conclusions}

In summary, a dinuclear $\mathrm{Au}(\mathrm{I})$ complex with a cyclic PNNP ligand $\left((\mathrm{AuCl})_{2} \mathrm{~L}\right)$ is highlighted as an efficient "host" molecule 
with nucleophilic "upper" and electrophilic "lower" binding sites. Organic molecules and cations are revealed as the "guests" inducing concentration-dependent changes in the emission of the complex. X-ray analysis data along with luminescent measurements performed at various guest concentrations and under conditions of competition between two guests for binding with the host point to structural requirements for efficient host-guest binding. In particular, the presence of two preorganized $\mathrm{Au}-\mathrm{Cl}$ moieties in the complex structure is the reason for its $1: 1$ binding via the "upper" binding site with organic cations. Ketone, formamide and sulfoxide derivatives are highlighted as guests for binding via both "upper" and "lower" sites. The binding via "lower" sites leads to changes in mutual arrangement of pyridyl moieties and P-Au bonds of the complex, which results in a more pronounced effect on the excited state energy relative to the binding via the "upper" site. Solvent molecules exemplified by DMSO, DMF and AN provide different effects on the complex capacity for the substrate response. This difference in turn results from the competitive binding of DMSO and DMF with the complex, which decreases its luminescence response to the substrates. The substrate-induced luminescence response is more pronounced in AN, which is in good agreement with the weaker acetonitrile binding via the both binding sites of the complex. To the best of our knowledge the present work for the first time reveals "host-guest" binding of organic molecules and cations with $\mathrm{Au}(\mathrm{I})$ complexes as a tool for tuning their luminescence in solutions.

\section{Acknowledgements}

Financial support from the Russian Science Foundation (grant 15-13-30031) is gratefully acknowledged.

\section{Notes and references}

1 J. Carlos Lima and L. Rodriguez, Chem. Soc. Rev., 2011, 40, 5442-5456.

2 A. L. Balch, Angew. Chem., Int. Ed., 2009, 48, 2641-2644.

3 V. W.-W. Yam and E. C.-C. Cheng, Chem. Soc. Rev., 2008, 37, 1806-1813.

4 J. C. Vickery, M. M. Olmstead, E. Y. Fung and A. L. Balch, Angew. Chem., Int. Ed. Engl., 1997, 36, 1179-1181.

5 O. S. Wenger, Chem. Rev., 2013, 113, 3686-3733.

6 C. Jobbágy and A. Deák, Eur. J. Inorg. Chem., 2014, 4434-4449.

7 J. R. Shakirova, E. V. Grachova, A. S. Melnikov, V. V. Gurzhiy, S. P. Tunik, M. Haukka, T. A. Pakkanen and I. O. Koshevoy, Organometallics, 2013, 32, 4061-4069.

8 K. Chen, C. E. Strasser, J. C. Schmitt, J. Shearer and V. J. Catalano, Inorg. Chem., 2012, 51, 1207-1209.

9 S. Coco, C. Cordovilla, C. Dominguez and P. Espinet, Dalton Trans., 2008, 6894-6900.

10 B.-C. Tzeng, W.-C. Lo, C.-M. Che and S.-M. Peng, Chem. Commun., 1996, 181-182.

11 X. He, W. H. Lam, N. Zhu and V. W.-W. Yam, Chem. - Eur. J., 2009, 15, 8842-8851.
12 V. Wing-Wah Yam, C.-K. Li and C.-L. Chan, Angew. Chem., Int. Ed., 1998, 37, 2857-2859.

13 C.-K. Li, X.-X. Lu, K. M.-C. Wong, C.-L. Chan, N. Zhu and V. W.-W. Yam, Inorg. Chem., 2004, 43, 7421-7430.

14 V. Wing-Wah Yam, K.-L. Cheung, E. Chung-Chin Cheng, N. Zhu and K.-K. Cheung, Dalton Trans., 2003, 1830-1835.

15 V. W.-W. Yam, K.-L. Cheung, L.-H. Yuan, K. M.-C. Wong and K.-K. Cheung, Chem. Commun., 2000, 1513-1514.

16 X. He and V. W.-W. Yam, Coord. Chem. Rev., 2011, 255, 2111-2123.

17 J. M. López-de-Luzuriaga, in Modern Supramolecular Gold Chemistry, Wiley-VCH Verlag GmbH \& Co. KGaA, 2009, vol. 6, pp. 347-401.

18 R. V. Bojan, R. Czerwieniec, A. Laguna, T. Lasanta, J. M. Lopez-de-Luzuriaga, M. Monge, M. E. Olmos and H. Yersin, Dalton Trans., 2013, 42, 4267-4277.

19 M. Trivedi, Bhaskaran, G. Singh, A. Kumar and N. P. Rath, J. Organomet. Chem., 2014, 758, 9-18.

20 N. Nasser and R. J. Puddephatt, Inorg. Chim. Acta, 2014, 409(Part B), 238-243.

21 X. He, F. Herranz, E. C.-C. Cheng, R. Vilar and V. W.-W. Yam, Chem. - Eur. J., 2010, 16, 9123-9131.

22 X. He, N. Zhu and V. W.-W. Yam, Organometallics, 2009, 28, 3621-3624.

23 I. O. Koshevoy, A. J. Karttunen, S. P. Tunik, M. Haukka, S. I. Selivanov, A. S. Melnikov, P. Y. Serdobintsev, M. A. Khodorkovskiy and T. A. Pakkanen, Inorg. Chem., 2008, 47, 9478-9488.

24 I. O. Koshevoy, L. Koskinen, M. Haukka, S. P. Tunik, P. Y. Serdobintsev, A. S. Melnikov and T. A. Pakkanen, Angew. Chem., Int. Ed., 2008, 47, 3942-3945.

25 I. O. Koshevoy, Y.-C. Lin, A. J. Karttunen, P.-T. Chou, P. Vainiotalo, S. P. Tunik, M. Haukka and T. A. Pakkanen, Inorg. Chem., 2009, 48, 2094-2102.

26 A. A. Karasik, A. S. Balueva, E. I. Musina and O. G. Sinyashin, Mendeleev Commun., 2013, 23, 237-248.

27 A. A. Karasik, R. N. Naumov, O. G. Sinyashin, G. P. Belov, H. V. Novikova, P. Lonnecke and E. Hey-Hawkins, Dalton Trans., 2003, 2209-2214.

28 I. D. Strelnik, E. V. Gracheva, E. I. Musina, V. V. Gurzhiy, A. A. Karasik and S. P. Tunik, CrystEngComm, 2016, 18, 7629-7635.

29 W. L. F. Armarego and C. L. L. Chai, Purification of Laboratory Chemicals, Butterworth-Heinemann, Oxford, 2009, 6th edn, pp. 88-444.

30 E. I. Musina, V. V. Khrizanforova, I. D. Strelnik, M. I. Valitov, Y. S. Spiridonova, D. B. Krivolapov, I. A. Litvinov, M. K. Kadirov, P. Lönnecke, E. Hey-Hawkins, Y. H. Budnikova, A. A. Karasik and O. G. Sinyashin, Chem. - Eur. J., 2014, 20, 3169-3182.

31 H. C. van der Plas and D. J. Buurman, Tetrahedron Lett., 1984, 25, 3763-3764.

32 Bruker, BrukerAXS Inc., Madison, Wisconsin, USA, 2.1 SAINTPlus. Data Reduction and Correction Program (Ver. 7.31A) edn, 2006, vol. Bruker Advanced X-ray Solutions.

33 G. M. Sheldrick, Bruker-Nonis, University of Göttingen, Germany, 1996. 
34 G. M. Sheldrick, Acta Crystallogr., Sect. A: Found. Crystallogr., 2008, 64, 112-122.

35 A. L. Spek, Acta Crystallogr., 2009, D65, 148.

36 F. Neese, Wiley Interdiscip. Rev.: Comput. Mol. Sci., 2012, 2, 73-78.

37 C. Adamo and V. Barone, J. Chem. Phys., 1999, 110, 6158-6170.

38 F. Weigend and R. Ahlrichs, Phys. Chem. Chem. Phys., 2005, 7, 3297-3305.

39 S. Grimme, J. Antony, S. Ehrlich and H. Krieg, J. Chem. Phys., 2010, 132, 154104.

40 A. D. Becke and E. R. Johnson, J. Chem. Phys., 2005, 123, 154101.
41 E. R. Johnson and A. D. Becke, J. Chem. Phys., 2005, 123, 024101.

42 S. Grimme, S. Ehrlich and L. Goerigk, J. Comput. Chem., 2011, 32, 1456-1465.

43 H.-Y. Chao, W. Lu, Y. Li, M. C. W. Chan, C.-M. Che, K.-K. Cheung and N. Zhu, J. Am. Chem. Soc., 2002, 124, 14696-14706.

44 S. S. Tang, C.-P. Chang, I. J. B. Lin, L.-S. Liou and J.-C. Wang, Inorg. Chem., 1997, 36, 2294-2300.

45 E. C.-C. Cheng, W.-Y. Lo, T. K.-M. Lee, N. Zhu and V. W.-W. Yam, Inorg. Chem., 2014, 53, 3854-3863.

46 J. R. Lakowicz, Principles of Fluorescence Spectroscopy, Springer US, 2006.

47 F. Eckert and A. Klamt, AIChE J., 2002, 48, 369-385. 